\title{
LA PRESTACIÓN SANITARIA EN EL ESTADO AUTONÓMICO: LAS INCONGRUENCIAS ENTRE EL MODELO COMPETENCIAL Y SU FINANCIACIÓN
}

\section{Health care in the Autonomous State: the inconsistencies between the competency model and its financing}

\author{
EVA SÁENZ ROYO \\ Universidad de Zaragoza \\ evasaenz@unizar.es
}

Cómo citar/Citation

Sáenz Royo, E. (2020)

La prestación sanitaria en el Estado autonómico: las incongruencias entre el modelo competencial y su financiación. Revista Española de Derecho Constitucional, 119, 119-149. doi: https://doi.org/10.18042/cepc/redc.119.04

\section{Resumen}

La Constitución española reservó al Poder Legislativo estatal la competencia para fijar los servicios fundamentales mínimos en sanidad (art. 149.1.16 CE), mientras que son las CC. AA. las competentes para su desarrollo legislativo y gestión. Durante estos más de cuarenta años de vigencia del texto constitucional se ha producido una progresiva descentralización en la gestión sanitaria, que culminaría en 2001, a la par de una importante centralización legislativa. Este reparto competencial contrasta con el sistema de financiación diseñado para la prestación sanitaria desde 2001. Un sistema en el que el peso de la responsabilidad de gasto recae fundamentalmente en las CC. AA. El presente trabajo hace un análisis del reparto competencial vigente en España en materia sanitaria y lo relaciona con el sistema de financiación diseñado, poniendo de manifiesto la incongruencia que al respecto existe en el diseño de la prestación sanitaria.

\section{Palabras clave}

Sanidad; competencias; financiación. 


\begin{abstract}
The Spanish Constitution reserved to the central legislative power the competence to establish the minimum fundamental services in health (art. 149.1.16 CE), while the Autonomous Communities are the competent ones for their legislative development and management. During these more than forty years of validity of the constitutional text there has been a progressive decentralization in health management, which would culminate in 2001, along with an important legislative centralization. This competence distribution contrasts with the financing system designed for healthcare provision since 2001. A system in which the weight of the responsibility for spending rests primarily with the Autonomous Communities. This paper analyzes the competency distribution in Spain in health matters and relates it to the financing system designed, showing the inconsistency that exists in this regard in the design of health care.
\end{abstract}

\title{
Keywords
}

Health; competencies; financing. 


\section{SUMARIO}

I. INTRODUCCIÓN. II. PRECEDENTES HISTÓRICOS: LA PROGRESIVA ASUNCIÓN DE RESPONSABILIDAD PÚBLICA EN ASISTENCIA SANITARIA. III. LA DISTRIBUCIÓN DE COMPETENCIAS EN LA CONSTITUCIÓN ESPAÑOLA DE 1978: 1. El debate constituyente en torno a la prestación sanitaria. 2. La asunción estatutaria de la competencia sobre prestación sanitaria. IV. LA PRÁCTICA DE LA DISTRIBUCIÓN COMPETENCIAL A TRAVÉS DE LA LEGISLACIÓN Y LA JURISPRUDENCIA CONSTITUCIONAL: 1. Las competencias estatales en prestación sanitaria según la legislación vigente. 2. Las competencias de las comunidades autónomas en prestación sanitaria. 3. La jurisprudencia del TC a raíz de los últimos conflictos competenciales en prestación sanitaria: una interpretación restrictiva respecto a la posibilidad de mejora autonómica: 3.1. La inconstitucionalidad de una ampliación de los sujetos con derecho al acceso a la asistencia sanitaria. 3.2. La inconstitucionalidad de la mejora en el copago de la prestación farmacéutica. V. LA FINANCIACIÓN DE LA SANIDAD. VI. CONCLUSIONES. FueNtes dOCUMENTALES. Biblografia.

\section{INTRODUCCIÓN}

La responsabilidad pública de la prestación sanitaria en España encuentra su primer reconocimiento jurídico en la Constitución española de la II República. Ya entonces el legislador estatal se considera como el máximo y primer responsable de la asistencia sanitaria, que también tendrá un alto grado de centralización durante el régimen franquista. Por su parte, la Constitución española reservó al Poder Legislativo estatal la competencia para fijar los servicios fundamentales mínimos en sanidad, mientras que son las CC. AA. las competentes para su desarrollo legislativo y gestión (art. 149.1.16 CE).

El presente trabajo tiene como objeto el análisis del reparto competencial vigente en Espańa en materia de asistencia sanitaria, así como el reparto en la responsabilidad de su financiación. Tras un breve análisis histórico en el que se sitúa el origen de la asunción pública de la prestación sanitaria, se estudia el reparto competencial en la Constitución de 1978, teniendo en consideración los debates constituyentes. A continuación, se analiza la práctica del reparto competencial operada durante estos más de cuarenta ańos de vigencia constitucional a través del análisis legislativo y jurisprudencial. Para ello se tiene en especial consideración la última jurisprudencia constitucional en la que se discute la capacidad de las CC. AA. para reducir el copago farmacéutico o incluir en la asistencia sanitaria a los inmigrantes ilegales excluidos en la 
legislación estatal. Por último, y una vez que conocemos con precisión el reparto de competencias, se analiza el reparto en la responsabilidad de gasto. Se incluye esta perspectiva desde la consideración de que, en materias prestacionales, como es la sanidad, es indisociable la perspectiva financiera de la competencial. De hecho, el reconocimiento de una competencia sustantiva exige de autonomía financiera para su financiación. De la congruencia de ambas perspectivas depende el funcionamiento real del sistema.

\section{PRECEDENTES HISTÓRICOS: LA PROGRESIVA ASUNCIÓN DE RESPONSABILIDAD PÚBLICA EN ASISTENCIA SANITARIA}

A lo largo de nuestra historia, las prestaciones sanitarias constituyen una parte fundamental de la beneficencia, dirigidas fundamentalmente a los pobres, por lo que su historia no se distinguirá de la de esta. De la dispensación de estas prestaciones se ocuparon primeramente manos privadas, especialmente religiosas o gremiales, hasta empezar a ser objeto de políticas de carácter local (municipales y provinciales). El municipio y la provincia han sido, pues, la etapa intermedia por la que ha pasado la transferencia de la dispensación de estas prestaciones de manos particulares al Estado (Carasa Soto, 1985: 61). Si bien hubo algún intento de previsión de asistencia sanitaria relativa a toda la población en 1823, tuvo poca aplicación (Aparicio Tovar, 1989: 173).

Frente a estas políticas parciales y sectoriales, dirigidas especialmente a los pobres, representará un salto cualitativo el reconocimiento del Estado social e intervencionista que opera la Constitución republicana de 1931 (García Pelayo, 1991: 18-19). La exigencia de garantizar un conjunto de prestaciones sociales que la doctrina alemana denomina "procura existencial» se plasmará por primera vez en nuestra historia en un texto constitucional, y más concretamente en el ámbito sanitario en el art. 43, al reconocer el derecho a la prestación de asistencia a los enfermos y ancianos, y protección a la maternidad y a la infancia. Nada hay en las Constituciones del siglo xIx que pueda considerarse precedente de estos artículos que no son sino introductores de los llamados derechos sociales (Palmer Valero, 1997: 149).

Esta tendencia a la igualdad material, cuyo precedente más próximo era la Constitución de Weimar, fue recibida por la doctrina española de la II República como expresión de la crisis del federalismo. Por tanto, frente al federalismo de corte liberal donde son las unidades territoriales las que asumen las incipientes políticas prestacionales por entonces vigentes, nota definitoria de la descentralización política que la Constitución republicana de 1931 sanciona es la retención por el centro de las políticas prestacionales, 
de las que el Estado se considera el máximo y primer responsable. En materia sanitaria, se reconocen al Estado las "bases mínimas» de la legislación sanitaria interior (art. 15.7). En cualquier caso, se reserva el Estado la posibilidad de dictar reglamentos para la ejecución de sus leyes (art. 20). Sería el claro precedente de la Constitución de 1978, pero la inestabilidad gubernamental impidió su desarrollo legislativo (Sáenz Royo, 2003: 176-177), más allá de la constitución de la Clínica del Trabajo, un centro médico asistencial destinado a las víctimas de accidentes laborales o enfermedades de tipo profesional (Maza Zorrilla, 2012: 84).

La centralización en materia sanitaria se intensificará durante el régimen franquista. A la vez que se mantenía una beneficencia acorde con los principios de nuestra historia tradicional, hizo su aparición el primer seguro obligatorio de enfermedad por ley de 14 de diciembre de 1942. De clara inspiración bismarkiana, se trata de un seguro sanitario obligatorio para los trabajadores con menores rentas, gestionado por el Instituto Nacional de Previsión y financiado en parte por el Estado y en parte por contribuciones de trabajadores y empresarios. Es interesante señalar que en el art. 34 se hace referencia a que los servicios sanitarios se realizarán en las instituciones de la sanidad pública, "con la debida separación de las personas asistidas por la Beneficencia y por el Seguro». Además de la asistencia médica primaria y la farmacéutica en lista cerrada (petitorio), este seguro incluía la hospitalización temporal y la atención a la maternidad en él integrada (Maza Zorrilla, 2012: 86).

Este seguro se desarrolló enormemente como consecuencia del proceso de expansión económica que surgió en nuestro país desde 1950, pero especialmente en los sesenta y principios de los setenta. El seguro obligatorio de enfermedad, desde su creación y su posterior reestructuración mediante el Decreto 2065/1974, de 30 de mayo, por el que se aprueba el texto refundido de la Ley General de la Seguridad Social, fue asumiendo mayor número de patologías dentro de su cuadro de prestaciones y, al mismo tiempo, fue progresivamente incluyendo mayor número de personas y colectivos dentro de su esquema de seguro sanitario.

\section{LA DISTRIBUCIÓN DE COMPETENCIAS EN LA CONSTITUCIÓN ESPAÑOLA DE 1978}

La Constitución española, a la vez que define en su art. 1 al Estado español como Estado social, construye en su título VIII el llamado Estado autonómico. Entendido el término Estado como Estado ordenamiento, las comunidades autónomas deberán expresar también ese carácter social y democrático propio del 
Estado de derecho instituido por la norma fundamental (Lucas Murillo de la Cueva, 1993: 136). Por tanto, la organización o complejo institucional al que la Constitución encarga ese cometido es la organización total del Estado y no exclusivamente el conjunto institucional del Estado central (Solozábal Echevarría, 1999: 64-65).

Prueba de ello es la sujeción genérica que establece el art. 9.1 CE de todos los poderes públicos - entre los que se incluyen, naturalmente, los Parlamentos de las comunidades autónomas - respecto de las normas constitucionales, y la atribución a aquellos, en el art. 9.2 CE, de la promoción de las condiciones para que los individuos alcancen la libertad e igualdad reales y efectivas. A ello hay que añadir las particulares garantías establecidas por el art. 53.3 CE respecto a los principios rectores del capítulo III del título I y su constitución expresa como una serie de medidas que han de orientar la acción de los "poderes públicos» en general ${ }^{1}$.

Para conocer los titulares competentes para el desarrollo de las políticas sociales prestacionales derivadas fundamentalmente de los mandatos previstos en el capítulo III del título I habrá que acudir al título VIII de la Constitución (art. 149 y, transitoriamente, art. 148.1), a lo previsto también en los EE. AA. $y$, excepcionalmente, a las leyes estatales de transferencia o delegación de competencias a favor de las CC. AA.

\section{EL DEBATE CONSTITUYENTE EN TORNO A LA PRESTACIÓN SANITARIA}

Respecto a las previsiones constitucionales competenciales en materia de sanidad, durante los debates constituyentes básicamente fueron dos las cuestiones discutidas.

En primer lugar, el carácter contributivo o no del sistema sanitario. Ya hemos señalado que, durante el régimen de Franco, la prestación de la asistencia sanitaria tenía una clara inspiración bismarkiana, era de carácter contributivo y estuvo íntimamente vinculada al haz de derechos de los trabajadores y de sus familias y, en consecuencia, al ámbito abarcado por el sistema de Seguridad Social. Ahora bien, la vinculación de estas prestaciones de asistencia sanitaria con el sistema de Seguridad Social dejaba fuera a importantes colectivos

\footnotetext{
Nuestro Alto Tribunal ha corrobora esta idea cuando señala: «Es evidente que entre estos poderes públicos se encuentran las Comunidades Autónomas y que la "legislación vigente" citada (en el art. 53.3) comprende tanto la legislación estatal como la emanada de los órganos legislativos de aquéllas» (STC 64/1982, de 4 de noviembre, FJ 2).
} 
sociales, habida cuenta del no desarrollo pleno sobre la base del principio de universalidad de ambos sistemas. La necesidad de que la protección de la salud se extienda a colectivos ajenos a los trabajadores explicaría que en los debates constituyentes fuera constante e indiscutido el reconocimiento de un derecho a la salud a todos los ciudadanos desvinculado del régimen público de Seguridad Social. De ahí la separación constitucional tanto en la distribución de competencias como en el capítulo referente a los principios rectores de política social y económica entre la regulación del derecho a la salud (arts. 43 y 149.1.16 CE) y el sistema de Seguridad Social (arts. 41 y 149.1.17 CE).

Esta separación competencial de la prestación sanitaria respecto al esquema de la Seguridad Social ha sido ratificada por la jurisprudencia del Tribunal Constitucional (por todas, STC 98/2004). La regulación normativa de la prestación sanitaria pertenece en el esquema constitucional al ámbito material «sanidad». Esto, como veremos, no resulta incompatible con que el legislador estatal vincule el régimen de acceso a la asistencia sanitaria en España, con cargo a fondos públicos, con el vínculo de la persona con la Seguridad Social (art. 1.1 del Real Decreto Ley 16/2012, que modifica el art. 3 de la Ley 16/2003) (STC 64/2017, de 25 de mayo, FJ 3). Según la STC 139/2016, FJ 5b), «la nueva regulación de la condición de asegurado del Sistema Nacional de Salud supone un cambio en la política de progresiva extensión de la asistencia sanitaria gratuita o bonificada, que se aprecia a partir de la creación del Sistema Nacional de Salud y de la gradual incorporación como titulares de las prestaciones de colectivos a los que no alcanzaba la condición de asegurado de la Seguridad Social». Ahora bien, en términos competenciales, ello no supone una mutación ni convierte a la sanitaria en prestación de la Seguridad Social. A efectos del sistema de distribución de competencias, la asistencia sanitaria, en todas sus vertientes prestacionales, se integra en el concepto material "sanidad interior» (art. 149.1.16 CE) y no en el de "Seguridad Social» (art. 149.1.17 CE) (STC 98/2004, FJ 5).

La segunda cuestión debatida en sede constituyente consistía en determinar las competencias que corresponderían al Estado y a las CC. AA. Aunque también se demandan competencias plenas tanto legislativas como ejecutivas para las CC. AA. ${ }^{2}$, son constantes las propuestas de legislación

2 En la enmienda núm. 202 que presenta el Grupo Parlamentario de la Minoría Catalana al Anteproyecto de Constitución a los efectos de modificar la redacción del art. 138 en su totalidad, se reservan a los territorios autónomos la legislación exclusiva y la ejecución en sanidad pública y política de higiene. 
básica estatal y desarrollo legislativo y ejecución de las CC. AA. ${ }^{3}$. De ahí que el texto inicial del Anteproyecto de la Constitución (BOE, de 5 de enero de 1978), que preveía la reserva al Estado de una genérica programación en materia de sanidad interior, además de la coordinación general (art. 138.18), ya en el art. 143.1.15 del Dictamen de la Comisión de Asuntos Constitucionales y Libertades Públicas sobre el Anteproyecto de Constitución (Boletín Oficial de las Cortes, de 1 de julio de 1978), se convierte en «bases y coordinación general de la Sanidad». Esta distribución competencial se mantendrá sin modificaciones hasta la finalización de los debates.

Por otra parte, el art. 148.1.21. ${ }^{\text {a }} \mathrm{CE}$ permite asumir a las comunidades autónomas competencias en materia de sanidad e higiene. A primera vista puede parecer contradictorio el hecho de que se permita asumir a las comunidades autónomas todas las competencias sobre la materia sanitaria, si bien el Estado, ya hemos visto, ostenta títulos competenciales que le permiten incidir sobre esta de manera significativa.

A esta imprecisión del art. 148 trata de dar coherencia la enmienda del Grupo Parlamentario del Partido Nacionalista Vasco defendida por Monforte Arregui en el debate en el Pleno del Congreso de los Diputados (Diario de Sesiones del Congreso de los Diputados, de 19 de julio de 1978). De la lectura de esta puede concluirse que la materia a la que se refieren ambos artículos es la misma, la sanidad en general. El hecho de que entre las competencias autonómicas se señale lisa y llanamente la competencia sobre sanidad e higiene debe interpretarse en relación con las competencias que se reservan al Estado en dicha materia, concretamente la legislación básica y la coordinación. En definitiva, las comunidades autónomas tendrían competencia de desarrollo legislativo y de ejecución en toda la materia sanitaria.

Según esta interpretación, todas las comunidades autónomas, incluso las de vía lenta y sin tener que esperar el transcurso de los cinco años que se exige para ampliar las competencias a las no exclusivas del Estado del art. 149,

3 Véanse el voto particular del Grupo Parlamentario Socialista del Congreso al art. 138 del anteproyecto; las enmiendas al art. 138 del anteproyecto núm. 101 (de los diputados Josep Verde i Aldea, Jon Paredes i Hernández y Josep Pau Pernau, pertenecientes a Minoría Catalana), 309 (Grupo Parlamentario Socialistes de Catalunya), 357 (Grupo Socialista del Congreso) y 664 (Grupo Parlamentario Vasco). En el debate en la Comisión de Asuntos Constitucionales y Libertades Públicas (Diario de Sesiones del Congreso de los Diputados, de 15 de junio de 1978), Vizcaya Retana, del Grupo Parlamentario Vasco, insiste en la necesidad de que al Estado le correspondan únicamente las bases mínimas sobre la sanidad interior. 
hubieran podido asumir desde un principio el desarrollo legislativo y la gestión de la asistencia sanitaria. Sin embargo, la práctica no ha sido esta.

En definitiva, la Constitución española de 1978 reservó al Poder Legislativo estatal la competencia para fijar los servicios fundamentales mínimos en sanidad. Es decir, siguiendo la práctica existente en otros Estados federales, se dio al centro un margen de discrecionalidad para fijar los servicios sanitarios mínimos, de manera que todos los españoles gocemos de una igualdad básica en esta materia. Además, según se deduce del texto constitucional, se pretende la creación de una asistencia sanitaria desvinculada de la Seguridad Social.

Por lo que se refiere a la coordinación general atribuida al Estado en materia sanitaria, adicional a la competencia legislativa básica (art. 149.1.16), la jurisprudencia constitucional establece las siguientes precisiones:

a) Aunque constituye un reforzamiento o complemento de la noción de bases, es una competencia distinta a la de fijación de las bases, como se desprende del hecho de que en el art. 149.1 CE no siempre que se habla de bases se habla también de coordinación general, si bien ésta, cuando se incluye, aparece salvo en una ocasión (149.1.15 CE) unida a la competencia sobre las bases (art. 149.1.13 y 149.1.16 CE); b) la competencia de coordinación general presupone lógicamente que hay algo que debe ser coordinado, esto es, presupone la existencia de competencias de las Comunidades en materia de sanidad, competencias que el Estado, al coordinarlas, debe obviamente respetar, pues nunca ni la fijación de bases ni la coordinación general deben llegar a tal grado de desarrollo que dejen vacías de contenido las correspondientes competencias de las Comunidades; c) la competencia estatal de coordinación general significa no sólo que hay que coordinar las partes o subsistemas (esto es, las competencias comunitarias) del sistema general de sanidad, sino que esa coordinación le corresponde hacerla al Estado; d) en consecuencia la coordinación general debe ser entendida como la fijación de medios y de sistemas de relación que hagan posible la información recíproca, la homogeneidad técnica en determinados aspectos y la acción conjunta de las autoridades sanitarias estatales y comunitarias en el ejercicio de sus respectivas competencias de tal modo que se logre la integración de actos parciales en la globalidad del sistema sanitario (SSTC 32/1083, de 28 de abril, FJ 2; 22/2012, de 16 de febrero, FJ 3, y 33/2017, de 1 de marzo, FJ 4) 4 .

4 Doctrinalmente se han hecho dos interpretaciones distintas de la competencia estatal en coordinación de la Sanidad. Aquella que mantiene un "concepto material» que la configura como una competencia sustantiva diferente del concepto de bases y aquella que la considera una competencia instrumental para el ejercicio de la competencia básica. Véase Sáenz Royo, 2003: 191-193. 


\section{LA ASUNCIÓN ESTATUTARIA DE LA COMPETENCIA SOBRE PRESTACIÓN SANITARIA}

La Constitución, al establecer diferentes techos competenciales en función del procedimiento de acceso a la autonomía, al dar carácter potestativo a la asunción de competencias y al encomendar la regulación de estas a los estatutos de autonomía, dado el procedimiento de aprobación de estos, posibilita que la asunción de competencias sanitarias difiera grandemente de una comunidad autónoma a otra. Pero los hechos han conducido a una práctica uniformidad de las comunidades autónomas.

La asunción estatutaria de competencias en materia de «sanidad e higiene» (art. 148.1.21 CE) se hizo por lo común como atribuciones de desarrollo legislativo y de ejecución ${ }^{5}$, y se tradujo en la práctica en legislación sanitaria propia del Estado liberal, fundamentalmente preventiva, y que consiste en la ordenación normativa de las actividades y productos que tienen un potencial lesivo para la salud humana. Es lo que ha venido en llamarse ejercicio de la autoridad sanitaria y que queda fuera de nuestro objeto de estudio.

El proceso de asunción por las comunidades autónomas de las competencias de gestión de los servicios sanitarios comenzó por aquellas cuyos respectivos estatutos les atribuían inicialmente la competencia para asumir la gestión de los servicios de la Seguridad Social ${ }^{6}$. Respecto a estas comunidades autónomas, el proceso se prolongó desde 1981, fecha en que se produjeron los traspasos a la Generalidad de Cataluña, hasta 1994, con la aprobación del acuerdo de traspaso a la comunidad autónoma de Canarias?. Hay que aclarar

5 Se asumieron estatutariamente con el carácter de exclusivas en el caso de Andalucía, Aragón o Islas Baleares, aunque esta asunción es sin perjuicio de las competencias estatales en materia de sanidad.

6 Art. 18.2 Estatuto de Autonomía del País Vasco, 17.2 Estatuto de Autonomía de Cataluña, 33.2 Estatuto de Autonomía de Galicia, 20.2 Estatuto de Autonomía de Andalucía, 38.2 Estatuto de Autonomía de la Comunidad Valenciana, y 54.1 Estatuto de Autonomía de Navarra. El Estatuto de Autonomía de Canarias no prevé hasta la reforma por LO 4/1996, de 30 de diciembre, la competencia de desarrollo legislativo y ejecución en materia de Seguridad Social, exceptuando el régimen económico (art. 32.18), y la competencia en ejecución de gestión de las prestaciones sanitarias y sociales del sistema de la Seguridad Social y de los servicios del Instituto Nacional de la Salud, Instituto Nacional de Servicios Sociales e Instituto Social de la Marina (art. 33.3).

7 Real Decreto 1517/1981, de 8 de julio, sobre traspasos de servicios de la Seguridad Social a la Generalidad de Cataluña en materia de Seguridad Social (INSALUD E INSERSO); Real Decreto 400/1984, de 22 de febrero, sobre traspaso a la Comunidad 
que la transferencia a las CC. AA. de los servicios sanitarios se hizo como transferencia de servicios de la Seguridad Social por cuanto su desvinculación de esta fue progresiva.

La transferencia al resto de las CC. AA. se interpretó viable desde el punto de vista jurídico a partir del momento en que los estatutos de estas comunidades autónomas incorporan ya el correspondiente título competencial de gestión de la asistencia sanitaria de la Seguridad Social, de acuerdo con el párrafo 17 del apartado 1 del art. 149 de la Constitución ${ }^{8}$. La asunción efectiva de la ejecución y gestión de estos servicios se produciría en diciembre de 2001. Casi todos los nuevos estatutos de autonomía aprobados desde 2006

Autónoma de Andalucía de las funciones y servicios del Instituto Nacional de la Salud; Real Decreto 1536/1987, de 6 de noviembre, sobre traspaso a la Comunidad Autónoma del País Vasco de las funciones y servicios del Instituto Nacional de la Salud (INSALUD); Real Decreto 1612/1987, de 27 de noviembre, sobre traspaso a la Comunidad valenciana de las funciones y servicios del Instituto Nacional de la Salud; Real Decreto 1679/1990, de 28 de diciembre, sobre traspaso a la Comunidad Autónoma de Galicia de las funciones y servicios del Instituto Nacional de la Salud; Real Decreto 1680/1990, de 28 de diciembre, sobre traspaso a la Comunidad Foral de Navarra de las funciones y servicios del Instituto Nacional de la Salud (INSALUD), y Real Decreto 446/1994, de 11 de marzo, sobre traspaso a la Comunidad Autónoma de Canarias de las funciones y servicios del Instituto Nacional de la Salud.

8 Art. 39.1.1 Estatuto de Autonomía de Aragón a partir de la LO 5/1996, de 30 de diciembre; art. 33.1 Estatuto de Autonomía de Castilla-La Mancha a partir de la LO 3/1997, de 3 de julio; art. 12.1.4 Estatuto de Autonomía de Murcia a partir de la LO 1/1998, de 15 de junio; art. 28.1.1 Estatuto de Autonomía de Madrid a partir de la LO 5/1998, de 7 de julio; art. 26.1 Estatuto de Autonomía de Cantabria a partir de la LO 11/1998, de 30 de diciembre; art. 12.13 Estatuto de Autonomía de Asturias a partir de la LO 1/1999, de 5 de enero; art. 11.1.14 Estatuto de Autonomía de La Rioja a partir de la LO 2/1999, de 7 de enero; art. 12.8 Estatuto de Autonomía de las Islas Baleares a partir de la LO 3/1999, de 8 de enero; art. 36.12 Estatuto de Autonomía de Castilla y León a partir de la LO 4/1999, de 8 de enero, y art. 9.13 Estatuto de Autonomía de Extremadura a partir de la LO 12/1999, de 6 de mayo.

9 Reales Decretos de traspasos de las funciones y servicios del INSALUD de 27 de diciembre de 2001 al Principado de Asturias (núm. 1471), a la Comunidad Autónoma de Cantabria (núm. 1472), a la Comunidad Autónoma de La Rioja (núm. 1473), a la Comunidad Autónoma de la Región de Murcia (núm. 1474), a la Comunidad Autónoma de Aragón (núm. 1475), a la Comunidad Autónoma de Castilla-La Mancha (núm. 1476), a la Comunidad Autónoma de Extremadura (núm. 1477), a la Comunidad Autónoma de Illes Balears (núm. 1478), a la Comunidad de Madrid (núm. 1479) y a la Comunidad de Castilla y León (núm. 1480). 
concretan, a veces con mucho detalle ${ }^{10}$, el alcance de la materia compartida en la prestación sanitaria, asumiendo la organización y control de los centros, servicios y establecimientos sanitarios ${ }^{11}$.

\section{LA PRÁCTICA DE LA DISTRIBUCIÓN COMPETENCIAL A TRAVÉS DE LA LEGISLACIÓN Y LA JURISPRUDENCIA CONSTITUCIONAL}

\section{LAS COMPETENCIAS ESTATALES EN PRESTACIÓN SANITARIA SEGÚN LA LEGISLACIÓN VIGENTE}

Con el objetivo de ampliación de la asistencia sanitaria a todos los ciudadanos se aprueba la Ley 14/1986, de 25 de abril, General de Sanidad (en adelante, LGS). En esta ley quedaron plasmadas las coordenadas básicas de lo que es un sistema sanitario asentado sobre el modelo de provisión pública directa de servicios sanitarios (art. 66.1 LGS) y sobre la idea del servicio de salud universalizado, aunque se aplazaron para un momento posterior el pleno desarrollo y la efectiva puesta en práctica de dicho sistema. En concreto, quedaron aplazados la universalización total de la asistencia sanitaria ${ }^{12} y$, en íntima conexión con este objetivo, el tránsito hacia un sistema de financiación basado en el sistema impositivo general y la aprobación de una regulación unificada del contenido de la asistencia sanitaria desvinculada de los diferentes regímenes de protección de la Seguridad Social. Al asumir la ley un sistema globalizador unitario, se sustrae la regulación de la asistencia sanitaria del INSALUD del esquema competencial del art. 149.1.1.17 y queda sometida, como así lo expresa también el preámbulo, a lo previsto en el art. 149.1.16.

Este título competencial en materia sanitaria, de acuerdo con la jurisprudencia constitucional, justifica, y aun exige, la existencia de un sistema sanitario único y global, cuyas claves fundamentales fueron perfiladas por el legislador estatal a través de la LGS bajo la denominación de Sistema Nacional

10 Véanse el art. 55.2 Estatuto de Autonomía de Andalucía; art. 117.3 Estatuto de Autonomía de Canarias, y art. 162.3 Estatuto de Autonomía de Cataluña.

11 Véanse el art. 162.1 del Estatuto de Autonomía de Cataluña; art. 55.1 Estatuto de Autonomía de Andalucía; art. 71.55 Estatuto de Autonomía de Aragón, y art. 117.1 Estatuto de Autonomía de Canarias.

12 El reconocimiento de la universalidad subjetiva de la ley al extender la asistencia sanitaria pública a toda la población espańola y a los ciudadanos extranjeros que tengan establecida su residencia en territorio nacional (arts. 1.2 y 3.2) se prevé que se hará de forma progresiva en la DT quinta. 
de Salud. La LGS opera un deslinde competencial entre el Estado y las comunidades autónomas en materia sanitaria que desarrolla los escuetos términos que aparecen en la Constitución y los estatutos. Además, en coherencia con su competencia en materia de coordinación, crea el Consejo Interterritorial del Sistema Nacional de Salud (CISNS).

Aunque el principio general del que parte la LGS es la atribución de las competencias sanitarias a las CC. AA. siempre que no se hayan reservado expresamente al Estado ${ }^{13}$, este se reserva numerosas y amplias competencias normativas que, sin llegar a excluir la posibilidad de regulaciones autonómicas en materia sanitaria, restringen fuertemente su ámbito potencial. De ahí que durante los ańos transcurridos desde la promulgación de la LGS hayan sido numerosas las disposiciones estatales legales y reglamentarias que han complementado o desarrollado las previsiones contenidas en esta, siendo muchas de ellas íntegramente ordenadoras de los supuestos de hecho que contemplan y de aplicación directa. Buen ejemplo de ello son las competencias reservadas al Estado en materia de fijación de la cartera de servicios, un instrumento primordial para asegurar la homogeneidad mínima en la prestación sanitaria.

De conformidad con el art. 8 de la Ley 16/2003, de 28 de mayo, de cohesión y calidad del Sistema Nacional de Salud (en adelante, LCC), modificado por el art. 2.1 del Real Decreto Ley 16/2012, la cartera común de servicios del Sistema Nacional de Salud se acordará en el seno del Consejo Interterritorial de Salud, en el que están presentes todas las comunidades autónomas, y se aprobará mediante real decreto. La actualización de la cartera de servicios se aprobará por orden del ministro de Sanidad y Consumo, igualmente, previo informe del Consejo Interterritorial (art. 21). A pesar de lo que pueda parecer, en realidad, el Consejo Interterritorial de Salud no tiene capacidad decisoria en el contenido de la cartera de servicios, ya que según el art. 71 LCC el Consejo solo podrá emitir recomendaciones al respecto y siempre «sin menoscabo de las competencias legislativas de las Cortes Generales y, en su caso, normativas de la Administración General del Estado». Por tanto, es la Administración General del Estado la competente para fijar el contenido de la cartera de servicios, aprobada por Real Decreto 63/1995, de 20 de enero, cuya principal aportación fue la ordenación y control de las prestaciones sanitarias básicas para todo el Sistema Nacional de Salud en un listado sistematizado.

La cartera de servicios comprende diversas modalidades. La cartera común básica, regulada en el art. 8 bis de la Ley 16/2003, añadido por el

13 Según el art. 41.2: «Las decisiones y actuaciones públicas previstas en esta Ley que no se hayan reservado expresamente al Estado, se entenderán atribuidas a las Comunidades Autónomas». 
art. 2.2 del Real Decreto Ley 16/2012, comprende todas las actividades asistenciales de prevención, diagnóstico, tratamiento y rehabilitación que se realicen en centros sanitarios y sociosanitarios, así como el transporte sanitario urgente; servicios todos ellos cubiertos íntegramente por financiación pública, sin coste directo para el usuario. La cartera común suplementaria, regulada en el art. 8 ter de la Ley 16/2003, ańadido por el art. 2.3 del Real Decreto Ley $16 / 2012$, incluye las prestaciones farmacéutica, ortoprotésica y de productos dietéticos, así como el transporte sanitario no urgente, quedando estas prestaciones sujetas a aportación de los usuarios. La cartera común de servicios accesorios (regulada en el art. 8 quater de la Ley 16/2003, ańadido por el art. 2.4 del Real Decreto Ley 16/2012) incluye todas aquellas actividades, servicios o técnicas que, sin carácter de prestación, no se consideran esenciales, pero son coadyuvantes o de apoyo para la mejora de patologías de carácter crónico, estando sujetos a aportación de los usuarios. También la Administración General del Estado debe resolver sobre la financiación pública y el precio de los medicamentos y productos sanitarios previamente autorizados ${ }^{14}$.

\section{LAS COMPETENCIAS DE LAS COMUNIDADES AUTÓNOMAS EN PRESTACIÓN SANITARIA}

El reconocimiento de una competencia estatal sobre las «bases y coordinación general de la sanidad» (art. 149.1.16 CE) conllevaba la posibilidad de que las CC. AA. asumieran su competencia de desarrollo legislativo y gestión a través de sus estatutos de autonomía (art. 149.3 CE). Actualmente, todas las comunidades autónomas han asumido dicha competencia en sus estatutos y también las funciones que venía desempeñando y los servicios que venía prestando el Instituto Nacional de la Salud (INSALUD), lo que supone una

14 Fijados por Real Decreto 9/1996, de 15 de enero, por el que se regula la selección de los efectos y accesorios, su financiación con fondos de la Seguridad Social o fondos estatales afectos a la sanidad y su régimen de suministro y dispensación a pacientes no hospitalizados. Véase también el Real Decreto Legislativo 1/2015, de 14 de julio, que aprueba el Texto Refundido de la Ley de garantías y uso racional de los medicamentos y productos sanitarias. Este texto refundido incorpora todas las novedades que se han ido introduciendo en la materia por vía, fundamentalmente, de decretos leyes. Así, el Real Decreto Ley 16/2012, de 20 de abril, de medidas urgentes para garantizar la sostenibilidad del Sistema Nacional de Salud y mejorar la calidad y seguridad de sus prestaciones, norma que establece la aportación de los beneficiarios al gasto farmacéutico en función de su capacidad económica (art. 102). 
descentralización completa de la asistencia sanitaria del Sistema Nacional de Salud, incluida la de la prestación farmacéutica ${ }^{15}$.

Esta distribución competencial en el ámbito sanitario impide hablar de un marco de implementación vertical y uniforme de la prestación sanitaria. La sustancial igualdad entre todas las comunidades autónomas en lo que hace a la asunción estatutaria de competencias en prestación sanitaria no debe hacer perder de vista que los estatutos de autonomía son simples «marcos procesuales» de referencia dentro los cuales las propias instituciones autonómicas deberán poner en práctica prioritariamente ciertos sectores competenciales de acuerdo con las necesidades sentidas en cada momento y lugar (Porras Nadales, 1993: 112-114).

En este sentido, las comunidades autónomas no solo pueden, ya que sus estatutos de autonomía lo permiten, concretar y ejecutar la legislación estatal sobre prestación sanitaria, sino que en el marco de desarrollo normativo también podrían complementarla, añadiendo, por ejemplo, nuevas prestaciones sanitarias o medicamentos, siempre que se mantenga una coherencia y coordinación con los reconocidos estatalmente y sean financiados con sus propios recursos. El deber de promover las condiciones para que la libertad y la igualdad del individuo y de los grupos en que se integra sean reales y efectivas y de remover los obstáculos que impidan o dificulten su plenitud (art. 9.2 CE), y más concretamente de garantizar prestaciones y servicios sanitarios (art. 43 $\mathrm{CE}$ ), que la Constitución impone a todos los poderes públicos parece exigir una interpretación generosa respecto a las posibilidades de las comunidades autónomas de complementar y mejorar las prestaciones sanitarias estatales en función de sus necesidades propias y a partir de sus propios recursos. En apoyo de esta posibilidad podría mencionarse tanto la reiterada jurisprudencia constitucional como la legislación estatal al respecto ${ }^{16}$. Así, señala el TC:

[...] esa necesaria uniformidad mínima, que corresponde establecer al Estado, asegurando así un nivel mínimo homogéneo o nivel de suficiencia de las

15 Según el art. 50 LGS: «En cada Comunidad Autónoma se constituirá un Servicio de Salud integrado por todos los centros, servicios y establecimientos de la propia Comunidad, Diputaciones, Ayuntamientos y cualesquiera otras Administraciones territoriales intracomunitarias, que estará gestionado como se establece en los artículos siguientes bajo la responsabilidad de la respectiva Comunidad Autónoma».

16 En contra de la posibilidad enriquecedora de las CC. AA. en materia sanitaria se manifiesta expresamente Aparicio Tovar al considerar que sería contrario a la «uniformidad de las condiciones de vida más allá del territorio de una Comunidad» y a la prohibición de privilegios establecida por el art. 138.2 CE (Aparicio Tovar, 1989: 139). 
prestaciones sanitarias públicas, puede ser susceptible de mejora, en su caso, por parte de las Comunidades Autónomas, en virtud de su competencia sustantiva y de su autonomía financiera, siempre y cuando, con ello, no se contravengan las exigencias que impone el principio de solidaridad (arts. 2 y $138 \mathrm{CE}$ ) (STC 98/2004, de 25 de mayo, FJ 7; en el mismo sentido, SSTC 64/2017 y 80/2017).

El catálogo de prestaciones sanitarias del Sistema Nacional de Salud, aprobado por Real Decreto 63/1995, de 20 de enero, salvaguarda las competencias de las CC. AA. para realizar actividades y prestaciones sanitarias "con cargo a sus propios recursos o financiadas mediante precios, tasas $\mathrm{u}$ otros ingresos propios, con arreglo a sus Estatutos de Autonomía y normas de desarrollo» (DA quinta). Así, también, el art. 8 quinquies LCC señala:

1. Las comunidades autónomas, en el ámbito de sus competencias, podrán aprobar sus respectivas carteras de servicios que incluirán, cuando menos, la cartera común de servicios del Sistema Nacional de Salud en sus modalidades básica de servicios asistenciales, suplementaria y de servicios accesorios, garantizándose a todos los usuarios del mismo. 2. Las comunidades autónomas podrán incorporar en sus carteras de servicios una técnica, tecnología o procedimiento no contemplado en la cartera común de servicios del Sistema Nacional de Salud, para lo cual establecerán los recursos adicionales necesarios. 3. Las Comunidades Autónomas deberán destinar los recursos económicos necesarios para asegurar la financiación de la cartera común de servicios, siendo preceptiva, para la aprobación de la cartera de servicios complementaria de una Comunidad Autónoma, la garantía previa de suficiencia financiera de la misma, en el marco del cumplimiento de los criterios de estabilidad presupuestaria.

Por tanto, la diversidad autonómica en relación con las bases estatales se admite bajo una serie de condiciones: mejor protección, título competencial propio, autonomía financiera y respeto del principio de solidaridad (Torres Pérez, 2017: 65). A ello se añade «la garantía previa de suficiencia financiera de la misma, en el marco del cumplimiento de los criterios de estabilidad presupuestaria». Esta nueva condición, añadida por el Real Decreto Ley 16/2012, fue declarada constitucional en la STC 139/2016 ${ }^{17}$.

Gracias al reconocimiento de esta posibilidad de mejora, las comunidades autónomas han ido incorporando algunas novedades. La primera fue referida a la prestación farmacéutica y consistió en la asunción por parte de Andalucía, a través del Decreto 195/1998, de la financiación pública de los medicamentos

17 Una crítica a dicha sentencia puede verse en Sobrino Guijarro, 2017: 86-87. 
excluidos por la normativa estatal contenida en el Real Decreto 1663/1998, de 24 de julio. La misma medida sería tomada poco después por Navarra (Decreto Foral 258/98). En esa misma línea, las distintas comunidades autónomas han ido aprobando otras mejoras en la cartera de servicios, siendo las más comunes la asistencia dental básica en determinadas franjas de la población (siguiendo el modelo de «Programa de Asistencia Dental Infantil»: País Vasco, Navarra, Andalucía, Aragón, Baleares, Canarias, Extremadura y Murcia) (Llena Puy et al., 2016), la ortodoncia dental para menores (Cantabria), métodos anticonceptivos $^{18}$, cirugía de cambio de sexo en transexuales (Andalucía, Madrid, Cataluña, País Vasco, Extremadura, Valencia, Murcia —Malagón, 2017- o Aragón) o financiación de productos ortoprotésicos (Andalucía, Galicia, Comunidad Valenciana) (Asenjo y Quiralte, 2003: 159-162).

No obstante, los márgenes de mejora que tienen las comunidades autónomas han sido precisados y matizados en recientes sentencias del Tribunal Constitucional a raíz de la aprobación del Real Decreto Ley 16/2012, de 20 de abril. Este real decreto ley introdujo dos novedades que han tenido repercusiones competenciales: la vinculación del acceso a la condición de asegurado (o beneficiario), que implicó la exclusión de los extranjeros en situación de irregularidad, y la exigencia de aportación de los beneficiarios a la prestación farmacéutica ambulatoria, el denominado "copago farmacéutico». A continuación, analizaremos estas precisiones jurisprudenciales respecto al ámbito de mejora que pueden realizar las CC. AA.

\section{LA JURISPRUDENCIA DEL TC A RAÍZ DE LOS ÚLTIMOS CONFLICTOS COMPETENCIALES EN PRESTACIÓN SANITARIA: UNA INTERPRETACIÓN RESTRICTIVA RESPECTO A LA POSIBILIDAD DE MEJORA AUTONÓMICA}

3.1. La inconstitucionalidad de una ampliación de los sujetos con derecho al acceso a la asistencia sanitaria

El art. 1 del Real Decreto Ley 16/2012, en tres sucesivos apartados, ha introducido, de una parte, importantes modificaciones en el régimen jurídico

18 El DIU de cobre lo financian todas las comunidades salvo Baleares, Cataluña, Madrid y Murcia. La píldora del día después la distribuyen gratuitamente con recursos propios nueve comunidades: Andalucía, Aragón, Baleares, Cantabria, Cataluña, Comunidad Valenciana, Extremadura, Galicia y Navarra. Véase Europa Press/Murcia (2016). España "suspende" en programas y financiación de anticonceptivos. 23-11-2016. Disponible en: https://bit.ly/2WadkpD (consulta: 14-1-2020). 
de los titulares y beneficiarios del Sistema Nacional de Salud, dando nuevo contenido al anterior art. 3 de la LCC, y, de otro lado, ha agregado los arts. 3 bis y 3 ter a la mencionada ley, regulando el régimen de reconocimiento y control de la condición de asegurado y la asistencia sanitaria en situaciones especiales. El Tribunal Constitucional, en sucesivas sentencias, ha calificado como formal y materialmente básico el conjunto de preceptos que delimitan el concepto de quienes hayan de tener acceso al catálogo de prestaciones del Sistema Nacional de Salud (SSTC 139/2016, de 21 de julio, FF. JJ. 8 a 10; 33/2017, de 1 de marzo, FJ 4; 63/2017, de 25 de mayo, FJ 4, y 64/2017, de 25 de mayo, FF. JJ. 3 y 4), así como dictado al amparo de la competencia estatal para la coordinación general de la sanidad la atribución a un organismo estatal de las funciones de reconocimiento y control de la condición de asegurado o beneficiario a efectos del derecho a la asistencia sanitaria pública (STC 33/2017, de 1 de marzo, FJ 4).

Por tanto, es al Estado al que correspondería fijar el estado de beneficiario del Sistema Nacional de Salud como condición previa para que las respectivas CC. AA. puedan emitir las tarjetas sanitarias y, con ellas, el derecho a la prestación sanitaria primaria y especializada. Fijado lo anterior, la novedad que respecto a la condición de beneficiario introdujo el Real Decreto Ley 16/2012, de 20 de abril, fue la exclusión como tales a ciertos colectivos de personas como los nacionales mayores de 26 años que no hubiesen accedido todavía a su primer empleo ${ }^{19}$ y los extranjeros sin autorización de residencia, salvo en los casos previstos en el art. 3 ter LCCSNS (urgencias, mujeres embarazadas y menores). Quedaba por determinar si la normativa básica estatal sobre la condición de beneficiario colmaba en su integridad el ámbito subjetivo del derecho de acceso a las prestaciones sanitarias, de tal manera que en el Sistema Nacional de Salud establecido para todo el territorio del Estado el derecho de acceso a la cartera de prestaciones sanitarias tenga el mismo nivel de cobertura subjetiva. Es decir, si las CC. AA. podían aumentar esa cobertura subjetiva.

La aplicación de las nuevas exclusiones resultó algo confusa entre las autonomías Diversas CC. AA. no aplicaron la exclusión y aprobaron diferentes normativas que otorgaban a los extranjeros sin autorización de residencia las prestaciones del servicio de salud autonómico en las mismas condiciones que los ciudadanos de la comunidad autónoma y previa observancia de determinados

19 Aunque se les reconocería posteriormente por el Decreto 1192/2012, de 3 de agosto, por el que se regula la condición de asegurado y de beneficiario a efectos de la asistencia sanitaria en España, con cargo a fondos públicos, a través del Sistema Nacional de Salud, siempre que no tuvieran unos ingresos anuales superiores a los 100000 euros. 
requisitos. Fue el caso de Asturias, Andalucía, Cataluña, País Vasco y Navarra ${ }^{20}$. Tras las elecciones de mayo de 2015, Valencia, Baleares, Aragón, Cantabria, Castilla-La Mancha y Extremadura modificaron su legislación para incluir en sus sistemas de salud a aquellos que se quedaron fuera en $2012^{21}$.

20 Véanse las Instrucciones de la Consejería de Sanidad, de 30 de agosto de 2012, para el Servicio de Salud del Principado de Asturias sobre la autorización de asistencia sanitaria, con carácter provisional, a las personas extranjeras en situación irregular sin recursos, con el fin de dar cumplimiento a lo establecido en la legislación sanitaria estatal y autonómica y para proporcionar a los profesionales de la sanidad pública unos criterios uniformes de actuación; las Instrucciones de 6 de junio de 2013, de la Dirección General de Asistencia Sanitaria y Resultados en Salud del Servicio Andaluz de Salud sobre el reconocimiento del derecho a la asistencia sanitaria en centros del Sistema Sanitario Público de Andalucía a personas extranjeras en situación irregular y sin recursos; la Instrucción 10/2012, de 30 de agosto, sobre el acceso a la asistencia sanitaria de cobertura pública del Servicio Catalán de Salud a los ciudadanos extranjeros empadronados en Cataluña que no tienen la condición de asegurados o beneficiarios del Sistema Nacional de Salud, derogada por la Ley 9/2017, de 27 de junio, de universalización de la asistencia sanitaria con cargo a fondos públicos mediante el Servicio Catalán de la Salud; el Decreto 114/2012, de 26 de junio, del Gobierno del País Vasco, sobre régimen de las prestaciones sanitarias del Sistema Nacional de Salud en el ámbito de la Comunidad Autónoma de Euskadi, y el Decreto Foral 117/2012, de 31 de octubre, por el que se modifica el Decreto Foral 640/1996, de 18 de noviembre, por el que se establecen el procedimiento y las condiciones para el acceso a las prestaciones del Régimen de Universalización de la Asistencia Sanitaria Pública en la Comunidad Foral de Navarra, derogado por la Ley Foral 8/2013, de 25 de febrero, por la que se reconoce a las personas residentes en Navarra el derecho de acceso a la asistencia sanitaria gratuita del sistema público sanitario de Navarra.

21 El Decreto Ley 3/2015, de 24 de julio, del Consell, por el que regula el acceso universal a la atención sanitaria en la Comunitat Valenciana; la Instrucción del director general del Servicio de Salud de 17 de julio de 2015, por la que se establece, con carácter de urgencia, los trámites que se han de llevar a cabo con el objeto de garantizar el derecho al acceso a la asistencia sanitaria de las personas extranjeras sin recursos económicos suficientes, en el ámbito de gestión del Servicio de Salud de las Illes Balears (anulada por la sentencia de la Sala de lo Contencioso-Administrativo del Tribunal Superior de Justicia de Illes Balears, de 5 de septiembre de 2017); la Instrucción de 7 de agosto de 2015, del consejero de Sanidad, por la que se regula el acceso a la asistencia sanitaria en Aragón para las personas extranjeras sin recursos económicos suficientes ni cobertura de asistencia sanitaria del Sistema Nacional de Salud; la Orden SAN/38/2015, de 7 de agosto, de la Consejería de Sanidad, por la que se regula la inclusión en el Sistema Sanitario Público de Cantabria de las personas residentes en la comunidad autónoma que no tengan acceso a un sistema de protección sanitaria pública; la Orden 9 de febrero de 2016, de la Consejería de Sanidad, 
El Gobierno de la nación presentó un recurso de inconstitucionalidad o un conflicto de competencia contra algunas de esas normas autonómicas (del País Vasco, Navarra, Valencia, Extremadura y Cataluña), al estimar que habían excedido las competencias autonómicas y vulnerado las atribuidas al Estado en determinados preceptos constitucionales. En las sucesivas sentencias que han resuelto estos procedimientos ${ }^{22}$ se ha declarado la inconstitucionalidad de las normas por incumplir la normativa básica estatal, excluyendo, así, la posibilidad de que una comunidad autónoma pueda ampliar los sujetos beneficiarios en el ámbito estatal ${ }^{23}$. En este sentido:

[...] la normativa básica estatal cierra toda posibilidad a las normas autonómicas de desarrollo para configurar un sistema de acceso a las prestaciones sanitarias que no atienda a los conceptos de asegurado o de beneficiario que han establecido las bases recogidas en el tantas veces citado artículo 3 de la Ley 16/2003, a excepción del supuesto residual de la suscripción del convenio especial previsto en el apartado quinto del citado precepto (STC 134/2017, de 16 de noviembre, FJ 5).

El Real Decreto Ley 7/2018, de 27 de julio, sobre el acceso universal al Sistema Nacional de Salud, vuelve a vincular la atención sanitaria a la condición

de acceso universal a la atención sanitaria en Castilla-La Mancha; la Ley extremeña 7/2016, de 21 de julio, de medidas extraordinarias contra la exclusión social.

22 SSTC 134/2017, de 16 de noviembre (para el Decreto vasco 114/2012, de 26 de junio); 145/2017, de 14 de diciembre (para el Decreto Ley valenciano 3/2015); 2/2018, de 11 de enero (para la Ley extremeńa 7/2016), y 17/2018, de 22 de febrero (para la Ley Foral 8/2013) y 18/2018, de 22 de febrero (para el Decreto Foral 117/2012). Del recurso de inconstitucionalidad promovido contra la Ley catalana 9/2017, el Gobierno desistió y el Tribunal Constitucional admitió el desistimiento y declaró extinguido el proceso en el ATC de 16 de octubre de 2018.

23 Por el contrario, consideran que el ámbito subjetivo «resulta ahora susceptible de mejora por las Comunidades Autónomas, con fundamento general en el principio de autonomía y fundamento específico en la competencia autonómica de desarrollo legislativo en materia de sanidad» los votos particulares a las SSTC seńaladas en la nota anterior de los magistrados don Fernando Valdés Dal-Ré, don Juan Antonio Xiol Ríos, don Cándido Conde-Pumpido Tourón y la magistrada doña María Luisa Balaguer Callejón. Igualmente, el voto particular que formula el magistrado don Antonio Narváez Rodríguez a las mismas sentencias.

También en contra de esta interpretación restrictiva de la competencia autonómica para mejorar el ámbito subjetivo de la prestación sanitaria se han pronunciado diferentes autores: Torres Pérez (2017: 77-79), Montilla Martos (2018: 2) y Delgado del Rincón (2019: 111-112). Sobre esta materia, véase también Marzal, 2017: 147-153 y 156-157. 
de ciudadano (y no de asegurado) y de «residencia en el territorio español», «con independencia de su nacionalidad». En lo que aquí interesa, pretende acabar con la situación de inseguridad jurídica y desigualdad en el acceso a la asistencia sanitaria que habían generado el Decreto Ley 16/2012 y las diversas normas autonómicas que se aprobaron para reaccionar contra él. Fue convalidado en el Parlamento en septiembre de 2018, aunque, a diferencia del Decreto Ley 16/2012, de 20 de abril, y de acuerdo con lo dispuesto en el art. $86.3 \mathrm{CE}$, se acuerda su tramitación como proyecto de ley por el procedimiento de urgencia, para que los grupos parlamentarios puedan proponer y debatir en la Cámara enmiendas y modificaciones al texto legal. A pesar de la pretensión de homogeneizar la asistencia sanitaria que se presta a los inmigrantes en situación irregular en las distintas comunidades autónomas, se incorporan algunas imprecisiones que podrían dar lugar a una diferente regulación autonómica. Así, el art. 3.ter.4 LCC habla de «documento certificativo» expedido por las comunidades autónomas para identificar a las personas extranjeras sin autorización de residencia a las que se les reconozca la prestación asistencial. Por tanto, las comunidades autónomas tendrían la competencia para regular todo lo relativo a la solicitud y expedición de ese documento acreditativo; competencia que podrían desarrollar de forma diferente y frustrar, así, uno de los objetivos de la nueva normativa (Delgado del Rincón, 2019: 130). A falta todavía de un reglamento que precise las ambigüedades del Decreto Ley 7/2018, el Ministerio de Sanidad ha elaborado unas Recomendaciones para el procedimiento de solicitud, registro y expedición del documento certificativo que acredita a las personas extranjeras que encontrándose en España no tengan residencia legal en territorio español, para recibir asistencia sanitaria. Como pone de manifiesto Delgado del Rincón, «la mayoría de las comunidades autónomas han adoptado el contenido de las recomendaciones ministeriales» (ibid.: 132).

\subsection{La inconstitucionalidad de la mejora en el copago de la prestación farmacéutica}

Respecto a la prestación farmacéutica, la jurisprudencia del Alto Tribunal ya había señalado el carácter básico de la legislación estatal que fija un mínimo en la financiación pública de la prestación farmacéutica. Así, la STC 98/2004, 25 de mayo, que resuelve un recurso de inconstitucionalidad contra la Ley del Parlamento de Canarias 5/1996, de 27 de diciembre, que establecía la capacidad del Gobierno para regular la fijación de los precios de referencia de grupos de medicamentos en el ámbito del Servicio Canario de Salud, señala: 
[...] la financiación pública del medicamento, a través del establecimiento de precios de referencia o sistema equivalente, es, ciertamente, un aspecto esencial o nuclear de la regulación de la prestación farmacéutica, al ser un presupuesto necesario para el acceso de los ciudadanos a los medicamentos en condiciones de igualdad, a precio razonable y con un precio público ajustado. Partiendo del carácter básico de la materia en cuestión dentro del marco normativo que regula la sanidad, forzosamente se ha de afirmar que es al Estado al que corresponde su regulación, en tanto que el art. 149.1.16 le otorga la competencia exclusiva sobre las «bases y coordinación general de la sanidad».

De esta forma se garantiza una uniformidad mínima en las condiciones de acceso a los medicamentos con independencia del lugar en el que dentro del territorio nacional se resida y se evita la introducción de factores de desigualdad en la protección básica de la salud. Sin embargo, esa necesaria uniformidad mínima, que corresponde establecer al Estado, asegurando así un nivel mínimo homogéneo o nivel de suficiencia de las prestaciones sanitarias públicas, puede ser susceptible de mejora, en su caso, por parte de las Comunidades Autónomas, en virtud de su competencia sustantiva y de su autonomía financiera, siempre y cuando, con ello, no se contravengan las exigencias que impone el principio de solidaridad (arts. 2 y $138 \mathrm{CE}$ ).

[...] Y siendo una de las citadas prestaciones el medicamento, es evidente que el acceso al mismo en condiciones de igualdad presupone necesariamente una regulación uniforme mínima y de vigencia en todo el territorio español que establezca un sistema de precios de referencia a los efectos de determinar el alcance de su financiación pública, de tal modo que quede garantizado a todos los ciudadanos, con independencia de la Comunidad Autónoma en que residan, el disfrute de medicamentos financiados públicamente al menos en un mismo porcentaje mínimo, susceptible, como ha quedado ya dicho, de ser incrementado en virtud de las disponibilidades financieras de cada Comunidad en cuestión (FJ 7).

En este caso, el TC declaró que, si la norma autonómica permitiera fijar unos precios para las diversas especialidades farmacológicas superiores a los mínimos establecidos por la norma básica estatal, sería inconstitucional. Se permite, pues, que la norma autonómica, respetando los mínimos estatales, mejore la prestación farmacéutica.

En la misma línea, admitiendo la posibilidad de mejora del servicio, pero no su empeoramiento, se sitúan las SSTC 71/2014, de 8 de mayo, y 85/2014, de 29 de mayo. Ambas sentencias declararon la inconstitucionalidad de la tasa autonómica conocida como el "euro por receta» establecida por la Ley de Cataluña 5/2012, de 20 de marzo, y por la Ley de la Asamblea de Madrid 
8/2012, de 28 de diciembre. Se consideran inconstitucionales porque hacían más gravoso para los beneficiarios el régimen de participación en el coste previsto por la norma estatal respecto a la prestación farmacéutica. El TC argumenta que la tasa condiciona de manera directa la prestación farmacéutica, ya que el pago es condición para la obtención del medicamento y, por lo tanto, perjudica a los ciudadanos de determinadas comunidades autónomas. Además, la tasa no recae sobre una nueva prestación prevista por las comunidades autónomas como parte de la cartera complementaria que pueden establecer en la definición de la política sanitaria propia, sino que recae sobre todas las prestaciones contempladas en cartera común suplementaria.

Esta línea jurisprudencial cambia en la STC 64/2017. En respuesta al recurso contra el Decreto Ley 16/2012 interpuesto por el Gobierno vasco, la novedad introducida por el Tribunal Constitucional es que, al reconocer la constitucionalidad del establecimiento por el legislador estatal de los importes máximos de financiación pública de la cartera común suplementaria y de la cartera común de servicios accesorios, impide una financiación añadida autonómica que reduciría la aportación del ciudadano. Con ello, si bien admite la posibilidad de mejora por parte de las comunidades autónomas, esta posibilidad de mejora la reduce a "la cartera de servicios complementaria», pero excluye una mejora que afecte a la cartera común básica, la común suplementaria y la común de servicios accesorios. Expresamente seńala la STC 64/2017:

[...] la previsión de establecimiento por el Estado de importes máximos de financiación de la cartera común suplementaria y de la cartera común de servicios accesorios tiene materialmente carácter básico; atiende a garantizar la uniformidad mínima en las condiciones de acceso a las prestaciones sanitarias, con independencia del lugar en el que dentro del territorio nacional se resida, evitando la introducción de factores de desigualdad en la protección de la salud. La cartera común de servicios del Sistema Nacional de Salud se articula en torno a las modalidades de cartera común básica, cartera común suplementaria y cartera común de servicios accesorios (financiadas en los términos que se establecen por los artículos 8 bis, 8 ter y 8 quater de la Ley 16/2003) y se configura como un mínimo básico, susceptible de mejora por las Comunidades Autónomas a través de la cartera de servicios complementaria. Esta, financiada con cargo a sus propios presupuestos, está sujeta a la exigencia de contar con «la garantía previa de suficiencia financiera de la misma en el marco del cumplimiento de los criterios de estabilidad presupuestaria» (FJ 5).

[...] En efecto, la definición de la modalidad de financiación aplicable a las diferentes prestaciones sanitarias, y en qué supuestos procede el pago de aportaciones por sus destinatarios, tiene una incidencia central en la forma de prestación del 
propio servicio, constituyendo así también un elemento nuclear del propio ámbito objetivo de las prestaciones sanitarias, que en consecuencia debe ser regulado de manera uniforme, por garantizar el mínimo común de prestaciones sanitarias cubierto por financiación pública en todo el territorio nacional (FJ 6).

En coherencia con estas argumentaciones, el Tribunal Constitucional en posteriores sentencias ha declarado la inconstitucionalidad de reducciones en el porcentaje de la aportación a la prestación farmacéutica ambulatoria o de la ampliación de los sujetos beneficiarios de la exención al copago. En este sentido, se ha declarado la inconstitucionalidad del Decreto vasco 114/2012, de 26 de junio (STC 134/2017, de 16 de noviembre), de la Ley Foral navarra 18/2012, de 19 de octubre (STC140/2017, de 30 de noviembre) o del Decreto Ley valenciano 3/2015, de 24 de julio (STC 145/2017, de 14 de diciembre) ${ }^{24}$.

\section{LA FINANCIACIÓN DE LA SANIDAD}

La financiación de la asistencia sanitaria pública se encuentra ya completamente desvinculada de la Seguridad Social, al haberse eliminado totalmente la aportación procedente de las cotizaciones sociales. Se asume, por tanto, una financiación de la sanidad vía impuestos. La cuestión es si esta financiación debería hacerse vía Presupuestos Generales del Estado y, por tanto, a través de impuestos estatales, o vía Presupuestos de las comunidades autónomas y, por tanto, a través de impuestos autonómicos.

La congruencia entre responsabilidad legislativa y responsabilidad de gasto exigiría que la financiación de los servicios se hiciera recaer sobre el que decide su implantación. En contra de este principio básico, nuestro sistema de financiación autonómica se diseña sobre la base de que sean las comunidades autónomas las que paguen lo que el Estado ha decidido, lo que se traduce en —como hemos visto- determinar quién accede al Sistema Nacional de Salud y las prestaciones sanitarias cubiertas.

Desde 2001, la financiación de los servicios sanitarios está subsumida en la financiación general de las comunidades autónomas. Es decir, la financiación

24 Se manifestan a favor de la posibilidad de reducción autonómica de la aportación del usuario los votos particulares a estas sentencias de los magistrados don Fernando Valdés Dal-Ré, don Juan Antonio Xiol Ríos, don Cándido Conde-Pumpido Tourón y la magistrada doña María Luisa Balaguer Callejón. Parte de la doctrina se ha manifestado igualmente en contra de la interpretación restrictiva de la capacidad de mejora en la prestación farmacéutica. Así, Torres Pérez, 2017: 72-73. 
sanitaria se deja en manos de las comunidades autónomas. Así se establece por el legislador estatal. Según el art. 10 LCC:

1. Las prestaciones que establece esta ley son responsabilidad financiera de las comunidades autónomas de conformidad con los acuerdos de transferencias y el actual sistema de financiación autonómica.

2. La suficiencia para la financiación de las prestaciones y de las garantías establecidas en esta ley viene determinada por los recursos asignados a las comunidades autónomas conforme a lo establecido en la mencionada Ley 21/2001, de 27 de diciembre, y de acuerdo con el principio de lealtad institucional, en los términos del artículo 2.1.e) de la Ley Orgánica 8/1980, de 22 de septiembre, de Financiación de las Comunidades Autónomas. 3. De acuerdo con el apartado anterior, la inclusión de una nueva prestación en el catálogo de prestaciones del Sistema Nacional de Salud se acompañará de una memoria económica que contenga la valoración del impacto positivo o negativo que pueda suponer. Dicha memoria se elevará al Consejo de Política Fiscal y Financiera para su análisis en el contexto de dicho principio de lealtad institucional.

Por lo tanto, la responsabilidad autonómica en la gestión sanitaria se ha traducido - mal- en la práctica en que las CC. AA. son las responsables principales en la financiación de esos servicios. Lo cual no es exactamente lo mismo. De hecho, en buena práctica federal, no debería serlo. Una cosa es la gestión y otra diferente es la responsabilidad de gasto.

Los recursos para la prestación sanitaria proceden de tributos propios autonómicos, impuestos parcialmente cedidos por el Gobierno central (patrimonio, sucesiones y donaciones, electricidad, transmisiones patrimoniales y actos jurídicos documentados) y participaciones en la recaudación de otros (50\% de IRPF e IVA, $60 \%$ de impuestos especiales sobre el alcohol, el tabaco y los hidrocarburos), así como de transferencias adicionales del Gobierno central para lograr la convergencia entre CC. AA. (Lobo, 2017: 88-89). En total, las comunidades autónomas asumen el 91,8\% del gasto total (Ministerio de Sanidad, Consumo y Bienestar Social, 2019: 21).

Una de las novedades incorporadas en 2009 fue la introducción del Fondo de Garantía de Servicios Públicos Fundamentales (FGSPF), que asigna el $70 \%$ de los recursos para que todas las comunidades autónomas proporcionen a sus ciudadanos, en condiciones de igualdad, educación, sanidad y servicios sociales. Se trata de una cesta común que se nutre en un $75 \%$ de la recaudación de los tributos cedidos y de las tasas, y se distribuye cada ańo con criterios de necesidad, generando transferencias niveladoras entre regiones en proporción a la población 
ajustada de cada región (Díaz de Sarralde, 2011: 85-99)25. Por tanto, la garantía en la uniformidad de la prestación sanitaria se financia a través de este fondo estatal con recursos procedentes fundamentalmente de tributos cedidos a las comunidades autónomas. Por otra parte, los ingresos tributarios autonómicos que no se integran en este fondo son los que verdaderamente disponen libremente las comunidades autónomas y que podrían invertirse en las posibles mejoras sanitarias. En definitiva, «una parte considerable del gasto sanitario de las comunidades autónomas viene condicionada por decisiones del Gobierno central» (Cuenca y González, 2015: 75).

El problema de origen se encuentra en la propia Constitución española - o más bien en la interpretación que se ha hecho de ella—, al prever que se consigne en los Presupuestos Generales del Estado una asignación a las CC. AA. para garantizar «un nivel mínimo en la prestación de los servicios públicos fundamentales en todo el territorio español» (art. 158.1). En su interpretación se ha considerado necesario el establecimiento de un fondo específico (el Fondo de Garantía de Servicios Públicos Fundamentales), similar al previsto en el párrafo segundo del mismo artículo (el Fondo de Compensación). Esta exégesis parece olvidarse de que el mínimo común en servicios fundamentales en asistencia sanitaria se ha garantizado ya en el art. 149.1.16 CE. La responsabilidad que tiene el Estado en esta materia de establecer unos mínimos en todo el territorio estatal exige, en el caso de los derechos prestacionales, la financiación estatal de esos mínimos en la propia memoria económica de la ley estatal básica, con cargo, eso sí, en los Presupuestos Generales del Estado. Es decir, en buena práctica federal no debería disociarse la responsabilidad de la decisión legislativa de la responsabilidad del coste de la decisión. Otra cuestión es que la gestión de las cantidades presupuestadas para garantizar los mínimos establecidos legalmente por el Estado pueda, según el sistema de distribución de competencias, ser descentralizada.

Además, el Estado podría, en ejercicio de su potestad de gasto, proponer - que no imponer - financiación a las comunidades autónomas para la consecución de objetivos entendidos de interés general y no incorporados en la legislación básica, siempre en el marco de las relaciones intergubernamentales. Aquí se enmarcarían las subvenciones estatales dirigidas a la promoción

25 Similar fondo se propone en el Informe de la Comisión de Expertos para la revisión del modelo de financiación autonómica de 2017. En este caso lo llaman Fondo Básico de Financiación (FBF), que «se formaría con la recaudación total de los tramos autonómicos del IVA e Impuestos Especiales (IIEE) que corresponda a las CC. AA. de régimen común y con un porcentaje de los ingresos normativos de estas por las demás figuras que se integran en la cesta de tributos cedidos» (Ministerio de Hacienda, 2017: 73). 
de actividades para la salud bucodental infantil (Real Decreto 111/2008, de 1 de febrero). Igualmente, se incluirían en su potestad de gasto las subvenciones a particulares y organizaciones, cuya gestión directa por el Estado ha sido justificada en algunos casos por el TC «dada la naturaleza y objetivos de las concretas acciones de que se trata (trasplantes de órganos; información, prevención, detección y tratamiento del SIDA; donación de sangre)» (STC 13/1992, de 6 de febrero, FJ 12A) o dado que se dirigen al desarrollo de programas de ámbito nacional, como las subvenciones a familias y organizaciones no gubernamentales sin ánimo de lucro para el desarrollo del Plan Nacional sobre Drogas, que «no admiten la compartición de su gestión en cada Comunidad Autónoma, o en los que su gestión descentralizada supone graves riesgos de ineficacia para el logro de los objetivos propuestos», formando parte estos programas «de las competencias básicas del Estado» (STC 13/1992, de 6 de febrero, FJ 13J).

En cualquier caso, no se puede olvidar que siempre que haya una distribución para la gestión descentralizada de fondos estatales condicionados habrá discusión sobre los criterios de reparto. A este respecto podría plantearse la necesidad de que los fijara una autoridad independiente, al estilo de la Commonwelth Grants Commission australiana (López Laborda, 2014: 13), o de carácter eminentemente técnico dependiente orgánicamente del Consejo de Política Fiscal y Financiera (Ministerio de Hacienda, 2017: 67).

Por último, habría que subrayar que la congruencia entre responsabilidad legislativa y de gasto se cumple con la exigencia de que las mejoras que introduzcan las CC. AA. en la cartera de servicios complementaria se hagan con cargo a sus presupuestos (art. 8 quinquies LCC). No obstante, el margen de maniobra que tienen las comunidades autónomas es reducido. Ya hemos seńalado que la jurisprudencia del Tribunal Constitucional impide una posible mejora en los sujetos que tengan acceso a la asistencia sanitaria, así como en la prestación farmacéutica. A esta dificultad se unirá la económica, ya que está muy restringido el campo de los impuestos propios. De hecho, se reconoce poder tributario a las comunidades autónomas al reconocer la posibilidad de fijar sus propios impuestos, tasas y contribuciones especiales, pero este se ve muy mermado por la prohibición de doble imposición y de duplicidad normativa. Según el art. 6.2 de la LOFCA, ya en su redacción original, señalaba que las comunidades autónomas no pueden establecer tributos que recaigan sobre hechos imponibles gravados por el Estado.

Esta limitación al poder tributario autonómico se ha visto intensificada por dos hechos. Por una parte, por la interpretación que el propio Tribunal Constitucional ha hecho de los límites constitucionales de doble imposición debido a la concurrencia impositiva entre los distintos niveles de gobierno. Por 
otra parte, por la actitud que de facto ha mostrado el Estado cuando el Tribunal Constitucional ha admitido un impuesto autonómico, forzando la concurrencia impositiva y evitando, así, la tributación propia autonómica (Sáenz Royo, 2018: 4382-4383).

\section{CONCLUSIONES}

Frente a una importante centralización legislativa en la conformación de los sujetos que tienen acceso al Sistema Nacional de Salud y la fijación de las prestaciones con financiación pública, la financiación sanitaria pública se hace recaer fundamentalmente en las comunidades autónomas. Se trata de una grave incongruencia entre el sistema de distribución de competencias vigente y su financiación.

El 17 de enero de 2017, fruto de la VI reunión de la Conferencia de Presidentes, se aprobó el acuerdo para «sostenibilidad del Estado de Bienestar y la reforma de la financiación autonómica». Como primer paso de esta se constituyó una comisión de expertos, cuyo informe fue publicado en el verano de 2017. En dicho informe se sigue partiendo de la premisa de que son fundamentalmente las comunidades autónomas las que han de financiar, en lo que aquí interesa, los servicios de sanidad (Ministerio de Hacienda, 2017: 39).

Un nuevo modelo de financiación habría de partir de la identificación entre la responsabilidad legislativa y la responsabilidad de gasto y, por tanto, de la exigencia al Estado de que financie con sus propios recursos los mínimos legalmente establecidos en materia de sanidad (art. 149.1.16 CE). No se trata, como señala el informe, de aumentar la capacidad normativa de las comunidades autónomas en la fijación de las bases del sistema de bienestar (pp. 17 y 84). Se trata de que, en virtud del propio sistema de reparto competencial constitucionalmente fijado, sea al Estado al que le corresponde la garantía de dichos mínimos con sus propios recursos. A partir de esos mínimos, tendrían que ser las autonomías, a través de tributos propios, las que decidieran o no su mejora, en correspondencia con la competencia de desarrollo de bases que tienen reconocida estatutariamente en el Estado de bienestar. Y en este ámbito resulta criticable tanto la reciente jurisprudencia del Tribunal Constitucional respecto a las posibilidades normativas de mejora por parte de las comunidades autónomas como la referente a la posibilidad de crear impuestos propios $^{26}$. El deber

26 A este respecto pueden ser interesantes recientes propuestas doctrinales sobre la necesidad de incrementar la responsabilidad fiscal de las comunidades autónomas a través de impuestos propios, con una armonización estatal. Así, se propone establecer una 
de promover las condiciones para que la libertad y la igualdad del individuo y de los grupos en que se integra sean reales y efectivas y de remover los obstáculos que impidan o dificulten su plenitud (art. 9.2 CE), y más concretamente de garantizar prestaciones y servicios sanitarios (art. $43 \mathrm{CE}$ ), que la Constitución impone a todos los poderes públicos parece exigir una interpretación generosa respecto a las posibilidades de las comunidades autónomas de complementar y mejorar las prestaciones sanitarias estatales en función de sus necesidades propias y a partir de sus propios recursos ${ }^{27}$.

La corrección de esta incongruencia entre responsabilidad legislativa y responsabilidad de gasto exigiría algunas correcciones jurisprudenciales y legislativas. Por una parte, sería necesaria una reorientación de la jurisprudencia constitucional para ser más generosa con las posibilidades de mejora de las comunidades autónomas con sus propios recursos. Por otra parte, resultaría imprescindible una reforma de la Ley Orgánica de la Financiación Autonómica que fuera acorde con la distribución constitucional de competencias en sanidad. Es decir, que reconociera la responsabilidad fiscal de las CC. AA. no respecto a lo que el legislador estatal decida, sino solo respecto a las mejoras que políticamente decidan sus Parlamentos.

\section{Bibliografía}

Aparicio Tovar, J. (1989). La Seguridad Social y la protección de la salud. Madrid: Civitas.

Asenjo, C. y Quiralte, A. (2003). Cobertura, acceso y nuevos derechos de los ciudadanos: el desarrollo de la normativa autonómica. Informe Anual del Sistema Nacional de Salud 2003. Anexo II. Madrid: Observatorio Nacional de la Salud. Disponible en: https://bit. ly/36HxHOX.

Carasa Soto, P. (1985). El sistema hospitalario español en el siglo XIX. De la asistencia benéfica al modelo sanitario actual. Valladolid: Publicaciones de la Universidad de Valladolid.

Cuenca, A. y González, R. (2015). Sistema de financiación autonómica y gasto sanitario en España. Papeles de Economía Española, 143, 75-93.

lista cerrada de tributos autonómicos y un ejercicio de la autonomía tributaria restringido tan solo a tipos impositivos, dejando en una ley estatal los tipos mínimos y máximos para cada impuesto (Martínez-Vázquez et al., 2019: 95).

27 En esta misma línea se pronuncian los votos particulares a las SSTC 134/2017, 145/2017, 2/2018, 17/2018 y 18/2018, de los magistrados don Fernando Valdés Dal-Ré, don Juan Antonio Xiol Ríos, don Cándido Conde-Pumpido Tourón y la magistrada dońa María Luisa Balaguer Callejón. Igualmente, el voto particular que formula el magistrado don Antonio Narváez Rodríguez a las mismas sentencias. 
Delgado del Rincón, L. E. (2019). Nuevos avances en la universalización de la asistencia sanitaria en Espańa: a propósito de la reforma apresurada, imprecisa e incompleta introducida por el Decreto Ley 7/2018, de 27 de julio. Revista de Estudios Políticos, 186, 105-136. Disponible en: https://doi.org/10.18042/cepc/rep.186.04.

Díaz de Sarralde, S. (2011). La garantía de servicios públicos fundamentales en el nuevo sistema de financiación de las Comunidades Autónomas. Presupuesto y Gasto Público, 62, 85-100.

García Pelayo, M. (1991). Las transformaciones del Estado contemporáneo. Madrid: Alianza Editorial.

Llena Puy, C. et al. (2016). La atención bucodental en comunidades autónomas con modelos público o mixto en España. Revista del Ilustre Consejo General de Colegios de Odontólogos y Estomatólogos de España, 23 (1), 14-22.

Lobo, F. (2017). Sanidad, restricciones presupuestarias y responsabilidad fiscal de las comunidades autónomas. En La economía, la innovación y el futuro del Sistema Nacional de Salud español. Madrid: Funcas.

López Laborda, J. (2014). Posibles reformas en la regulación constitucional de la financiación autonómica. Fedea Policy Papers, 2014/2. Disponible en: https://bit.ly/38KBfku.

Lucas Murillo de la Cueva, P. (1993). El Estatuto como programa y el control y la participación en la política económica y social como exigencias del Estado social. En G. Cámara Villar y J. Cano Bueso (eds.). Estudios sobre el Estado social. El Estado social y la Comunidad Autónoma de Andalucía. Madrid: Tecnos.

Malagón, P. (2017). En España, es gratis el cambio de sexo, pero el dentista es de pago. Mediterráneo Digital, 25 de junio de 2017. Disponible en: https://bit.ly/2MfX0ye (consulta 14-1-2020).

Martínez-Vázquez, J. et al. (2019). A propósito del Informe de la Comisión de Expertos para la revisión del modelo de financiación autonómica: oportunidades para un sistema más eficiente. Presupuesto y Gasto Público, 96, 89-106.

Marzal Yetano, E. (2017). Crisis y competencia por la competencia: el ejemplo de la inmigración. Revista de Derecho Político, 98, 121-158. Disponible en: https://doi.org/10.5944/ rdp.98.2017.18653.

Maza Zorrilla, E. (2012). Antecedentes. En G. Escobar Roca (dir.). Derechos sociales y tutela antidiscriminatoria. Pamplona: Aranzadi.

Ministerio de Hacienda (2017). Informe de la Comisión de Expertos para la revisión del modelo de financiación autonómica. Disponible en: https://bit.ly/3foItx8 (consulta: 14-1-2020).

Ministerio de Sanidad, Consumo y Bienestar Social (2019). Gasto Sanitario. Informe Anual del Sistema Nacional de Salud 2018. Informes, Estudios e Investigación.

Montilla Martos, J. A. (2018). La doctrina del Tribunal sobre las bases. Competencias cada vez menos compartidas. Revista catalana de dret públic [blog], 9-1-2020. Disponible en: https://doi.org/10.5944/rdp.101.2018.21972.

Palmer Valero, R. (1997). Los problemas socioeconómicos en la Constitución de 1931. Madrid: Centro de Estudios Políticos y Constitucionales.

Porras Nadales, A. (1993). El desarrollo del Estado social intervencionista en la Comunidad Autónoma de Andalucía. En G. Cámara Villar y J. Cano Bueso (eds.). Estudios sobre el Estado social: el Estado social y la Comunidad Autónoma de Andalucía. Madrid. Tecnos. 
Sáenz Royo, E. (2003). Estado social y descentralización politica. Una perspectiva constitucional comparada de EE. UU., Alemania y España. Madrid: Thomson-Civitas.

- (2018). La financiación autonómica después de cuarenta ańos: laberinto inextricable y reforma imprescindible. En B. Pendás (dir.). España constitucional (1978-2018): trayectorias y perspectivas (pp. 4377-4389). Madrid: Centro de Estudios Políticos y Constitucionales.

Sobrino Guijarro, I. (2017). Contenido constitucional del derecho a la protección de la salud a la luz de la STC 139/2016. Ius et Scientia, 3 (1), 79-88. Disponible en: https://doi. org/10.12795/IETSCIENTIA.2017.i01.08.

Solozábal Echevarría, J. J. (1999). El Estado social como Estado autonómico. Teoría y Realidad Constitucional, 3, 61-78. Disponible en: https://doi.org/10.5944/trc.3.1999.7186.

Torres Pérez, A. (2017). Autonomía política y Estado social ante la crisis económica: la tendencia a la uniformidad territorial en menoscabo de la diversidad de políticas sociales. Revista Vasca de Administración Pública, 109, 57-88. 